\title{
Anterior composite restorations in clinical practice: findings from a survey with general dental practitioners
}

Flávio Fernando DEMARCO ${ }^{1,2}$, Rudimar Antonio BALDISSERA ${ }^{1}$, Francine Cardozo MADRUGA ${ }^{1}$, Roberto Cuchiara SIMÕES ${ }^{3}$, Rafael Guerra LUND ${ }^{1}$, Marcos Britto CORREA ${ }^{1}$, Maximiliano Sérgio CENCI ${ }^{1}$

\footnotetext{
1- Post-Graduate Program in Dentistry, Federal University of Pelotas, Pelotas, RS, Brazil.

2- Post-Graduate Program in Epidemiology, Federal University of Pelotas, Pelotas, RS, Brazil.

3- Private Practice, Pelotas, RS, Brazil.
}

Corresponding address: Flávio Fernando Demarco - Programa de Pós-Graduação em - Odontologia - FOUFPel - Rua Gonçalves Chaves, 457 - Sala 504 - Centro - Pelotas - RS. - 96015-560 - Fone/fax: 55-533222-6690 R.135 - e-mail: flavio.demarco@pq.cnpq.br - ffdemarco@gmail.com

Submitted: January 8, 2013 - Modification: August 22, 2013 - Accepted: September 10, 2013

\section{ABSTRACT}

\begin{abstract}
$\mathrm{O}$ bjectives: The aim of this study was to assess technical preferences of general dental practitioners when restoring anterior composite restorations. How the level of clinical experience or post-graduate training influenced their options was also tested. Material and Methods: A cross-sectional study was performed using a questionnaire with general dental practitioners (GDPs) $(n=276)$ in Southern Brazil. Information regarding postgraduation training (specialization, master's or PhD degree) and clinical experience (years since completing graduation) were gathered. The options regarding anterior composite restorations (type of composite, adhesive system, light curing unit, polishing procedures and rubber dam use) were collected. Data were submitted to descriptive analysis and associations were tested. Results: Response rate was 68\% (187). GDPs selected microhybrid composite (52\%) and 2-step total etch adhesive system (77\%). LED was the preferred method of activation for $72.8 \%$. Immediate polishing was preferred by $75 \%$, using a combination of techniques. Most of the respondents $(74.3 \%)$ did not use rubber dam. More experienced clinicians used more halogen lights $(p<0.022)$, performed more light monitoring $(p<0.001)$ and were resistant to use rubber dam $(p<0.012)$. Dentists with post-graduation training used 3 -etch-and-rinse system more frequently $(p<0.04)$, usually monitored light intensity $(p<0.014)$ and placed rubber dam more frequently $(p<0.044)$. Conclusions: Hybrid composite, simplified adhesives, LED units and immediate polishing were preferred by Southern Brazilian dentists for anterior composite restorations. Few dentists used rubber dam to perform composite restorations in anterior teeth. Clinical experience and post-graduation training influenced the dentists' choices.
\end{abstract}

Key words: Dental resins. Dental materials. Surveys. Dentist-patient relations. Dentinbonding agents.

\section{INTRODUCTION}

Since their introduction in Dentistry, composites have suffered remarkable changes in their composition, which have resulted in significant improvement in materials properties ${ }^{2,8,12,29}$. These materials have become more popular for

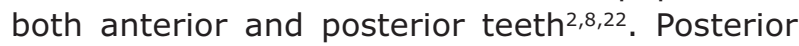
composite restoration can have a long lifespan with a low annual failure rate $8,11,27$. There are few results from long term clinical trials evaluating composite in anterior teeth ${ }^{2}$, but the short term studies show good performance ${ }^{22}$.

When dentists perform anterior composite restorations, the selection of materials and equipment, including the type of composite, the type of adhesive system, and the kind of light curing unit, may influence mechanical properties and ultimately affect clinical performance ${ }^{2,22}$. Several different composites are available in the market, 
including: microfilled composites, providing a more polishable surface; hybrid composites jointing resistance and smooth surface; and more recently the composites with nanofillers, offering several advantages over the previously available composites ${ }^{12,21,26}$. Adhesive systems have also undergone significant modifications and currently there is a large range of adhesive systems available to clinicians, including two-step and three-step etch-and-rinse systems and the two-step and onestep self-etch systems ${ }^{9,24}$. The simplification of the technique reduces the possibility of professional error and the total time to perform composite restoration ${ }^{6}$, but some studies have demonstrated that the traditional three-step etch-and-rinse adhesive systems produce better and long lasting restorations ${ }^{9,24}$.

Many factors affect the polymerization of light activated composite and the choice of a light-curing unit ${ }^{20,23}$. Quartz-tungsten halogen (QTH) lights used to be the preferred method of composite activation, but light-emitting diode (LED) units have gained popularity in the market and in clinical practice ${ }^{15,16}$, and currently LEDs have demonstrated deeper polymerization capacity, higher lamp lifespan, and lower heat generation ${ }^{12,23}$. In addition, while QTH light units require constant monitoring, in LED units such routine monitoring is not mandatory ${ }^{15,25}$.

Besides the type and brand of dental materials and equipments, clinical variables may significantly affect the performance of composite restorations $s^{4,51,27}$. Rubber dam application provides a better control of humidity, making the restorative procedure easier as clinicians do not need to worry about contamination of the operative field ${ }^{13,19}$. In addition, clinical reports have discussed that restoration longevity could be influenced by rubber dam isolation ${ }^{2,4}$.

Additionally, polishing of composite restorations may impact in the maintenance of a smoother surface, less susceptible to staining, wear, bacterial adhesion and potentially reducing the risk of secondary caries occurrence $3,6,14,17$. Mediate or immediate polishing seem to produce similar results $^{6,28}$. Several materials or sequence of materials are indicated for polishing procedures, producing different results, depending on the composite chosen ${ }^{28}$.

The clinical experience of the dentist can influence the selection of restorative procedures and treatment longevity $4,8,11,27$. While more time in clinical practice could improve the dentist's ability, the fast evolution of restorative materials requires a constant educational update for professionals in order to keep them updated on new materials and techniques ${ }^{5}$. Post-graduation training in different levels can provide this valuable update throughout the teaching of new material properties and training their applications ${ }^{18}$. Questionnaire surveys have been used to evaluate the dentists' preferences regarding different procedures performed in the dental office ${ }^{10,18}$.

This study evaluated the preferences of Brazilian dentists in relation to the materials and techniques used for anterior composite restorations, using a questionnaire survey. A secondary investigation was the influence of years in clinical practice and post-graduate training on preferred practices.

\section{MATERIAL AND METHODS}

This study had the approval of the Ethics Committee, School of Dentistry, Federal University of Pelotas. This was a cross-sectional study performed in the city of Pelotas, Southern Brazil, between March and June 2009. Dentists registered $(n=276)$ in the Brazilian Dentistry Council, sectional of Pelotas, formed the population of the study ${ }^{10}$.

Data were collected through a self-applied closed questionnaire. Some professional characteristics were investigated: clinical experience (time since concluding dental school, collected in years and then categorized in periods - $<10$ years, $10-20$ years, 20-30 years, and >30 years); post-graduation training (none, specialization level, master's degree or PhD degree, and then dichotomized in none and specialist, placing together all those dentists that attended formal post-graduation courses). Finally, information regarding their preferences when preparing anterior composite restorations were also included in the questionnaire, such as: the type of composite used for anterior restoration (microhybrid, microfilled, nanohybrid, flowable), type of adhesive system [two-step etch and rinse (acid+primer/adhesive), three-step etch-and-rinse (acid+primer+adhesive), two-step self-etching (acid primer+adhesive), and one-step self-etching (acid/primer/adhesive)], light unit used [quartztungsten-halogen - QTH, Light emitting diode LED, other (Laser, Plasma ARC, etc)], use of rubber dam (yes/no), the time of polishing (immediate, 24 hours, seven days) and the materials used for polishing (Diamond burs, zinc aluminum oxide disks, silicon abrasive points, or association of materials). The questionnaire did not include information that enabled the identification of the dentist and it was pre-tested with professionals (20) not enrolled in the study, working in private and public practice in a neighbor city, with similar characteristics ${ }^{10}$.

The questionnaires were personally delivered to each dentist's office and an explanation was given about the importance of their participation and the objectives of the study. After one week, 
in a second visit to the offices, the questionnaires were recovered, together with the signed informed consent to participate in the study. When the dentists did not return the questionnaire in a third visit, they were considered as dropouts.

Data were submitted to descriptive analyses to determine the prevalence of dentists' preferences and the respective $95 \%$ confidence intervals. Additionally, the association between clinical experience and post-graduation training and their selections was tested with Chi-square or Fisher exact test. The analyses were carried out with the Stata 10.0 (StataCorp, College Station, TX, USA) software package. The level of significance was determined as $p \leq 0.05$.

\section{RESULTS}

The response rate in this study was $68 \%$ (187 dentists). Losses and refusals were mainly due to the lack of questionnaire return or lack of signature on the informed consent form. Since the questionnaire was self-applied, clinicians have not answered some questions and accordingly the number of answers for each question presented variations.

Descriptive analysis is found in Table 1 . In relation to the gender, $52.4 \%$ were females. In relation to clinical experience, $45.4 \%$ of the respondents had less than 10 years of clinical practice. In relation to post-graduate training, $64 \%$ of the dentists interviewed had some kind of formal continuing education training (specialization, master's Degree, or PhD) and among those, 80\%

Table 1- Number of observations and frequencies of the studied variables among dentists $(n=187)$

\begin{tabular}{|c|c|c|}
\hline Variables & $\mathrm{n}^{*}$ & $\%(\mathrm{Cl} 95 \%)$ \\
\hline Type of composite & 169 & \\
\hline Microhybrid & 83 & $52.2(44.3-59.8)$ \\
\hline Microfilled & 42 & $26.4(20.1-34.0)$ \\
\hline Nanohybrid & 26 & $16.4(11.3-26.0)$ \\
\hline Flow & 5 & $3.1(1.0-6.8)$ \\
\hline I don't know & 3 & $1.9(0.4-5.1)$ \\
\hline Type of adhesive & 161 & \\
\hline 2-step total etch & 124 & $77.0(70.4-83.8)$ \\
\hline 3-step total etch & 25 & $15.5(10.3-22.1)$ \\
\hline 2-step self-etching & 5 & $3.1(1.0-7.1)$ \\
\hline 1-step self-etching (all-in-one) & 7 & $4.4(1.8-8.8)$ \\
\hline Type of light unit & 173 & \\
\hline QTH & 43 & $24.86(18.60-31.98)$ \\
\hline LED & 126 & $72.83(65.56-79.30)$ \\
\hline Other & 4 & $2.3(0.6-5.8)$ \\
\hline Light Unit monitoring & 172 & \\
\hline Monthly & 14 & $8.1(4.5-13.3)$ \\
\hline Semester & 31 & $18.0(12.6-24.6)$ \\
\hline Annual & 47 & $27.3(20.8-34.6)$ \\
\hline I don't know/l don't perform & 80 & $46.5(38-9-54.3)$ \\
\hline Time of polishing procedures & 164 & \\
\hline Immediate & 123 & $75.0(67.7-81.4)$ \\
\hline 24 hours & 19 & $11.6(7.1-17.5)$ \\
\hline 7 days & 22 & $13.4(8.6-19.6)$ \\
\hline Type of polishing & 163 & \\
\hline Ultrafine Diamond burs & 23 & $14.1(9.2-20-4)$ \\
\hline Flexible zinc aluminum oxide disks & 12 & $7.4(3.9-12.5)$ \\
\hline Silicon abrasive points & 27 & $16.6(11.2-23.2)$ \\
\hline Combination of materials & 101 & $62.0(54.0-69.4)$ \\
\hline Rubber dam usage & 187 & \\
\hline No & 139 & $74.3(67.5-80-4)$ \\
\hline Yes & 48 & $25.7(19.6-32.6)$ \\
\hline
\end{tabular}

* Number of valid observations.

$\mathrm{Cl}=$ Confidence Interval QTH=quartz-tungsten halogen

LED=light-emitting diode 
had performed specialization courses.

In relation to the type of composite used for anterior teeth, microhybrid was selected by $52.2 \%$ (95\%CI 44.3-59.8), while the adhesive system preferred was the 2-step total etch technique with (95\%CI 70.4-83.3). LEDs were the light unit chosen for $72.8 \%$ (95\%CI 65.6-79.3) of the participants, and $46.5 \%$ (95\%CI 38.9-54.3) of the respondents were not verifying the intensity of their light sources.

Regarding polishing procedures, $75 \%$ (95\%CI 67.7-81.4) of the clinicians performed the immediate polishing, using a combination of techniques (62\%; 95\%CI 57.7-81.4). In relation to rubber dam, $74.3 \%$ ( $95 \% \mathrm{CI} 67.5-80.4)$ of those interviewed were not using it in their routine to restore anterior teeth with composite resin.

In Table 2, it was possible to verify the association of clinical practice and the tested variables. Dentists with more years in clinical practice used more commonly QTH light curing units $(p<0.022)$ and performed with higher frequency the light monitoring $(p<0.033)$. Rubber dam usage was significantly associated with clinical experience $(p<0.012)$, with lower prevalence of use between those dentists with $<10$ years $(81 \%)$ and those with more than 30 years $(86.7 \%)$ in clinical practice.

Table 3 summarizes the association of restorative procedures and the post-graduation training. It was observed that those dentists with post-graduation training used more frequently three-step etch-and-rinse adhesive system $(p<0.04)$, monitored more frequently the light unit source $(p<0.005)$, and used rubber dam with higher frequency $(p<0.044)$.

Table 2- Association between the time of clinical practice (since completing dental school) of dentists and variables related to practices for anterior composite restorations

\begin{tabular}{|c|c|c|c|c|c|c|}
\hline & \multicolumn{6}{|c|}{ Time since graduation $\mathbf{n}(\%)$} \\
\hline & Up to 10 & 11 to 20 & 21 to 30 & $>30$ & Total & $p$ \\
\hline Type of composite & & & & & & 0.390 \\
\hline Microhybrid & $45(58.4)$ & $17(51.5)$ & $10(50.0)$ & $11(57.9)$ & $83(55.7)$ & \\
\hline Microfilled & $16(20.8)$ & $10(30.3)$ & $9(45.0)$ & $5(26.3)$ & $40(26.8)$ & \\
\hline Nanohybrid & $16(20.8)$ & $6(18.2)$ & $1(5.0)$ & $3(15.8)$ & $26(17.5)$ & \\
\hline Type of adhesive & & & & & & 0.862 \\
\hline 2-step total etch & $63(84.0)$ & $27(87.1)$ & $19(82.6)$ & $14(77.8)$ & $123(83.7)$ & \\
\hline 3-step total etch & $12(16.0)$ & $4(12.9)$ & $4(17.4)$ & $4(22.2)$ & $24(16.3)$ & \\
\hline Type of light unit & & & & & & 0.022 \\
\hline QTH & $14(16.9)$ & $10(28.6)$ & $8(33.3)$ & $9(36.0)$ & $41(24.6)$ & \\
\hline LED & $69(83.3)$ & $25(71.4)$ & $16(66.7)$ & $16(64.0)$ & $126(75.5)$ & \\
\hline Light Unit monitoring & & & & & & $<0.001$ \\
\hline Yes & $32(38.6)$ & $25(67.6)$ & $14(56.0)$ & $19(76.0)$ & $90(52.9)$ & \\
\hline No & $51(61.5)$ & $12(32.4)$ & $11(44.0)$ & $6(24.0)$ & $80(47.1)$ & \\
\hline Time of polishing & & & & & & 0.604 \\
\hline Immediate & $66(80.5)$ & $23(67.7)$ & $18(78.3)$ & $16(69.6)$ & $123(75.9)$ & \\
\hline After $24 \mathrm{~h}$ or latter & $16(195)$ & $11(32.4)$ & $5(21.7)$ & $7(30.4)$ & $39(24.1)$ & \\
\hline Type of polishing & & & & & & 0.209 \\
\hline Ultrafine Diamond burs & $7(8.9)$ & $5(14.7)$ & $5(21.7)$ & $6(24.0)$ & $23(14.3)$ & \\
\hline Flexible zinc aluminum oxide disks & $5(6.3)$ & $2(5.9)$ & $3(13.1)$ & $2(8.0)$ & $12(7.5)$ & \\
\hline Silicon abrasive points & $19(24.1)$ & $4(11.8)$ & $1(4.4)$ & $2(8.0)$ & $26(16.2)$ & \\
\hline Combination of materials & $48(60.8)$ & $23(67.7)$ & $14(60.9)$ & $15(60.0)$ & $100(62.1)$ & \\
\hline Rubber dam usage & & & & & & 0.012 \\
\hline No & $68(81.0)$ & $25(58.1)$ & $19(67.9)$ & $26(86.7)$ & $138(74.6)$ & \\
\hline Yes & $16(19.1)$ & $18(41.9)$ & 9 (32.1) & $4(13.3)$ & $47(25.4)$ & \\
\hline
\end{tabular}


Table 3- Association between the post-graduation training of dentists and variables related to practices for anterior composite restorations

\begin{tabular}{|c|c|c|c|c|}
\hline & \multicolumn{4}{|c|}{ Post-Graduation training n (\%) } \\
\hline & No & Yes & Total & $p$ \\
\hline Type of composite & & & & 0.629 \\
\hline Microhybrid & $35(61.4)$ & 48 (53.9) & 83 (56.9) & \\
\hline Microfilled & $15(26.3)$ & $26(29.2)$ & $41(28.1)$ & \\
\hline Nanohybrid & $7(12.3)$ & $15(16.9)$ & $22(15.1)$ & \\
\hline Type of adhesive & & & & 0.040 \\
\hline 2-step total etch & $52(91.2)$ & $68(78.2)$ & $120(83.3)$ & \\
\hline 3-step total etch & $5(8.8)$ & $19(21.8)$ & $24(16.7)$ & \\
\hline Type of light unit & & & & 0.988 \\
\hline QTH & $17(26.2)$ & $26(26.3)$ & $43(26.2)$ & \\
\hline LED & $48(73.9)$ & $73(73.7)$ & $121(73.8)$ & \\
\hline Light Unit monitoring & & & & 0.014 \\
\hline Yes & $26(40.6)$ & $62(60.2)$ & $88(52.7)$ & \\
\hline No & $38(59.4)$ & $41(39.8)$ & $79(47.3)$ & \\
\hline Time of polishing & & & & 0.287 \\
\hline Immediate & $50(79.4)$ & $69(71.9)$ & $119(74.8)$ & \\
\hline After $24 \mathrm{~h}$ or latter & $13(20.6)$ & $27(28.2)$ & $40(25.2)$ & \\
\hline Type of polishing & & & & 0.588 \\
\hline Ultrafine Diamond burs & $12(19.1)$ & $11(11.5)$ & $23(14.5)$ & \\
\hline Flexible zinc aluminum oxide disks & $4(6.4)$ & $8(8.3)$ & $12(7.6)$ & \\
\hline Silicon abrasive points & $10(15.9)$ & $15(15.6)$ & $25(15.7)$ & \\
\hline Combination of materials & $37(58.7)$ & $62(64.6)$ & $99(62.3)$ & \\
\hline Rubber dam usage & & & & 0.044 \\
\hline No & 55 (83.3) & $81(69.8)$ & $136(74.7)$ & \\
\hline Yes & $11(16.7)$ & $35(30.2)$ & $46(25.3)$ & \\
\hline
\end{tabular}

QTH=quartz-tungsten halogen

LED=light-emitting diode

\section{DISCUSSION}

When analyzing the findings of our study, it was possible to observe that the majority of dentists preferred to use microhybrid composite for anterior composite restorations, followed by microfilled and nanohybrid composites. Microhybrid composites are considered universal materials and may be applied in both anterior and posterior teeth², jointing the resistance properties of hybrid composites and the polishing characteristics of microfilled composites ${ }^{12,29}$. These "universal" materials show adequate clinical performance in long term in anterior or posterior restorations ${ }^{2}$. Probably these are the reasons accounting for the popularity of the microhybrid composites in the present study. Microfilled composites were selected for $25 \%$ of the participants. These materials were developed to produce a smoother surface, similar to enamel, increasing the aesthetic appearance ${ }^{3}$. They are not indicated in stress bearing areas, being indicated for anterior teeth or Class $\mathrm{V}$ in posterior teeth ${ }^{1}$. Nanohybrid composites are a new class of material and some studies have demonstrated that they could present advantages in relation to microhybrid composites ${ }^{21,26}$. Because they are relatively new materials, less known by dentists and with higher prices, they were probably less selected in our study.

The preferred adhesive system for the dentists in this survey was the two-step etch-and-rinse system $(77 \%)$, followed by three-step etchand-rinse system (15\%). Two-step systems appeared in the dental market with the purpose of simplifying the adhesive procedures, reducing time of application and the possibility of error during adhesive technique ${ }^{9}$. With such advantages, these adhesive systems gained popularity and 
they are sold by high profile dental materials distributers. Although more complex to use, threestep adhesive systems have exhibited in some laboratory and clinical studies a more reliable and strong bonding to dentin ${ }^{9,24}$. Despite good results in different studies observed for self-etching adhesive systems, they accounted for a small part of the respondents and this could be a result of Brazilian market, where the self-etching systems are still not popular.

In relation to the type of light source used, LED was selected for more than $70 \%$ of the dentists, while QTH lights were used for about one quarter of those interviewed. In opposition, Hao, et al. ${ }^{15}$ (2013) observed that the majority of light-curing units used by Chinese dentists were QTH units, with several years of use. Also, the authors observed that dentists were not aware of the need of periodic testing and maintenance. LED units were introduced by the end of 90's, and at that time the results were not promising when compared to QTH units ${ }^{23}$. Currently, with the evolution of LED units, the energy produced is similar or higher than QTH, with polymerization deepness comparable to the traditional QTH units ${ }^{7,16}$, and reducing the polymerization shrinkage. Additionally, LED units produce low heat and the units will last several times longer than halogen lights $7,15,16,20$.

Half of the dentists did not monitor their light units. Similarly, previous studies also verified that the majority of dentists were not aware that the light curing units require periodic testing and maintenance ${ }^{15,25}$. While for LED units the need for energy monitoring is less required, since LED units are able to keep the irradiance stable for long time, for QTH units these monitoring should be mandatory and weekly performed $15,20,25$.

Regarding polishing procedures, $3 / 4$ of the respondents performed polishing immediately after restorations. Traditionally, it was believed that professionals should wait for at least 24 hours to make polishing procedures, because the immediate polishing could damage restorations margins, decreasing restoration longevity ${ }^{3,6}$. However, several studies have demonstrated no detrimental effect of immediate polishing on microhardness, microleakage, surface roughness of composites ${ }^{6,28}$. The dentists also preferred the combination of materials to perform polishing procedures and this choice could reflect the understanding that such combination could provide a smother surface, increasing restoration aesthetic and durability ${ }^{6,28}$.

In relation to rubber dam application, $75 \%$ of the dentists usually performed anterior composite restorations without rubber dam. Similar low rate of dentists have indicated the use of rubber dam for clinical procedures in other countries ${ }^{13,18,19}$. Rubber dam provides a drier field, preventing moisture contamination that impairs adhesive procedures ${ }^{2,22}$. However, its placement increases the complexity of the restorative technique, the patient's chair time, and the price of restorations ${ }^{18,19}$. It is noteworthy that some studies have disclosed similar results when composite restorations were performed with or without rubber dam application ${ }^{4}$.

The years in clinical practice had a significant impact in relation to the following variables: type of light curing unit use; frequency of light curing unit monitoring; and rubber dam isolation. Since LED units are relatively new equipment in Dentistry when compared to QTH units, it would be expected that they would be more used by younger professionals. Also, older dentists are more conservative to introduce new technologies in their practices. More than $3 / 4$ of the dentists with more than 30 years of clinical practice monitored the energy of their light units, while less than $40 \%$ of those with less than 10 years in clinical practice perform this monitoring. The main reason for such finding is related to the higher use of LED by younger professional and these units did not require constant monitoring, while older dentists use more frequently QTH units, in which case energy checking is mandatory. Younger (less than 10 years) and older dentists (more than 30 years) were more resistant in using rubber dam, compared to dentists with intermediate careers (from 11 to 30 years of lifework). Brazilian Dentistry market is highly competitive and dentists in the beginning of their careers need to reduce the prices and attend more patients to increase their profits. Since rubber dam placement increases the time of treatment and produces an additional cost in this treatment, younger dentists may opt to avoid this additional cost and extra-time. Older dentists probably attended dental schools when rubber dam placement was not an usual practice. Previous reports have demonstrated the influence of time in clinical practice and the use of rubber $\operatorname{dam}^{13,18,19}$.

When evaluating the influence of postgraduation training, it was observed to affect the selection of adhesive systems, frequency of light unit monitoring and rubber dam application. Dentists that attended post-graduation courses are more likely to be more familiar with dental literature and participate more frequently in dental meetings, resulting in changes in their practices. Indeed, specialists selected three-step etch-and-rinse system with a higher frequency $(2.5 x)$ than non-specialists. The scientific literature demonstrates a superior performance of these traditional adhesive systems compared to simplified ones ${ }^{9,24}$. Specialists $(60 \%)$ checked more frequently the energy of light curing units 
than non-specialists (40\%) and such result could reflect the higher level of information of these professionals concerning the monitoring of light units to produce an effective polymerization of adhesive materials. The higher usage of rubber dam by specialists could reflect the major concern of these professionals with technique sensitive procedures.

This study has also some limitations. It was based on a self-applied closed questionnaire survey. Questionnaires are a useful tool to evaluate how dentists are selecting their materials and techniques in clinical practice and to evaluate the level of information they have in relation to the recent advances in material evolution and new techniques ${ }^{11,18-19}$. In the present study we used a self-applied closed questionnaire, which is easy to apply, allowing the dentists to complete the questionnaire without interruptions to their daily practice. However, the disadvantage of self-application is that it requires another visit of research team and sometimes the professional will not answer all the questions present in the questionnaire. In our study, the response rate obtained was $68 \%$ and losses and refusals were reduced since we visited the dental offices at least twice trying to recover the questionnaires. This response rate is acceptable, since response rates of around $50 \%$ have been reported in comparable surveys ${ }^{18,19}$. Moreover, the high level of agreement on certain questions could imply that these responses are generalizable to the overall GDP population in Southern Brazil.

\section{CONCLUSION}

The results of this study showed a preference of dentists when performing anterior composite restorations for microhybrid composite, 2-step total etch adhesive system, LED curing units, immediate polishing and association of materials to perform this polishing.

Also, it was possible to observe that the time of clinical practice and the attendance to continuing education courses influenced the decisions of clinicians in relation to the restorative procedures.

\section{CLINICAL RELEVANCE}

Dentists' attitudes and practices in relation to anterior composite restoration can be influenced by formation characteristics, such as the time elapsed since dentist graduation and continuing professional development.

\section{REFERENCES}

1- Al-Khayatt AS, Ray-Chaudhuri A, Poyser NJ, Briggs PF, Porter RW, Kelleher MG, et al. Direct composite restorations for the worn mandibular anterior dentition: a 7-year follow-up of a prospective randomised controlled split-mouth clinical trial. J Oral Rehabil. 2013;4(5):389-401.

2- Baldissera RA, Corrêa MB, Schuch H, Collares K, Nascimento GG, Jardim PS, et al. Are there universal restorative composites for anterior and posterior teeth? J Dent. 2013;41(11):1027-35.

3- Barbosa SH, Zanata RL, Navarro MF, Nunes OB. Effect of different finishing and polishing techniques on the surface roughness of microfilled, hybrid and packable composite resins. Braz Dent J. 2005; 16:39-44.

4- Brunthaler A, König F, Lucas T, Sperr W, Schedle A. Longevity of direct resin composite restorations in posterior teeth. Clin Oral Investig. 2003; 7:63-70.

5- Burke FJ, Lucarotti PS, Holder R. Outcome of direct restorations placed within the general dental services in England and Wales (Part 4): influence of time and place. J Dent. 2005;33:837-47.

6- Cenci MS, Venturini D, Pereira-Cenci T, Piva E, Demarco FF. The effect of polishing techniques and time on the surface characteristics and sealing ability of resin composite restorations after one-year storage. Oper Dent. 2008;33:169-76.

7- Chang HS, Cho KJ, Park SJ, Lee BN, Hwang YC, Oh WM, et al. Thermal analysis of bulk filled composite resin polymerization using various light curing modes according to the curing depth and approximation to the cavity wall. J Appl Oral Sci. 2013;21:293-9. 8- Da Rosa Rodolpho PA, Donassollo TA, Cenci MS, Loguércio AD, Moraes RR, Bronkhorst EM, et al. 22-Year clinical evaluation of the performance of two posterior composites with different filler characteristics. Dent Mater. 2011;27:955-63.

9- De Munck J, Van Landuyt K, Peumans M, Poitevin A, Lambrechts $P$, Braem $M$, et al. A critical review of the durability of adhesion to tooth tissue: methods and results. J Dent Res. 2005;84:118-32. 10- Demarco FF, Conde MCM, Ely C, Torre EM, Costa JRS, Fernández $M L$, et al. Preferences on vital and nonvital thooth blushing a survey among dentists from a city of Southern Brazil. Braz Dent J. 2013;24. Epub ahead of print.

11- Demarco FF, Corrêa MB, Cenci MS, Moraes RR, Opdam NJ. Longevity of posterior composite restorations: not only a matter of materials. Dent Mater. 2012;28:87-101.

12- Ferracane JL. Resin composite - state of the art. Dent Mater. 2011;27:29-38.

13- Gilbert GH, Litaker MS, Pihlstrom DJ, Amundson CW, Gordan VV, DPBRN Collaborative Group. Rubber dam use during routine operative dentistry procedures: findings from the Dental PBRN. Oper Dent. 2010;35:491-9.

14- Güler AU, Güler E, Yücel AC, Ertaş E. Effects of polishing procedures on color stability of composite resins. J Appl Oral Sci. 2009; 17:108-12.

15- Hao X, Luo M, Wu J, Zhu S. A survey of power density of light-curing units used in private dental offices in Changchun City, China. Lasers Med Sic. 2013;10.1007/s10103-013-1351-0 [Epub ahead of print].

16- Leprince J, Devaux J, Mullier T, Vreven J, Leloup G. Pulpal temperature rise and polymerization efficiency of LED curing lights. Oper Dent. 2010;35:220-30.

17- Lima FG, Romano AR, Correa MB, Demarco FF. Influence of microleakage, surface roughness and biofilm control on secondary caries formation around composite resin restorations: an in situ evaluation. J Appl Oral Sci. 2009;17:61-5.

18- Lynch CD, McConnell RJ. Attitudes and use of rubber dam by Irish general dental practitioners. Int Endod J. 2007;40:427-32. 19- Mala S, Lynch CD, Burke FM, Dummer PM. Attitudes of final year dental students to the use of rubber dam. Int Endod J. 2009;42:632-8.

20- Mitton BA, Wilson $\mathrm{NH}$. The use and maintenance of visible light activating units in general practice. Br Dent J. 2001;191:82-6. 
21- Moraes RR, Gonçalves LS, Lancellotti AC, Consani S, CorrerSobrinho L, Sinhoreti MA. Nanohybrid resin composites: nanofiller loaded materials or traditional microhybrid resins? Oper Dent. 2009;34:551-7

22- Moura FR, Romano AR, Lund RG, Piva $E$, Rodrigues Júnior SA, Demarco FF. Three-year clinical performance of composite restorations placed by undergraduate dental students. Braz Dent J. 2011;22:111-6.

23- Nomoto R, McCabe JF, Nitta K, Hirano S. Relative efficiency of radiation sources for photopolymerization. Odontology. 2009;97:109-14.

24- Peumans M, De Munck J, Van Landuyt KL, Poitevin A, Lambrechts $P$, Van Meerbeek B. A 13-year clinical evaluation of two three-step etch-and-rinse adhesives in non-carious class- $V$ lesions. Clin Oral Investig. 2012;16:129-37.
25- Santini A, Turner S. General dental practitioners' knowledge of polymerization of resin-based composite restorations and light curing unit technology. Br Dent J. 2011;211:E13.

26- Saunders SA. Current practicality of nanotechnology in dentistry. Part 1: Focus on nanocomposite restoratives and biomimetics. Clin Cosmet Investig Dent. 2009;1:47-61.

27- Van de Sande FH, Opdam NJ, Rodolpho PA, Correa MB, Demarco FF, Cenci MS. Patient risk factors' influence on survival of posterior composites. J Dent Res. 2013;92:78S-83S.

28- Venturini D, Cenci MS, Demarco FF, Camacho GB, Powers JM. Effect of polishing techniques and time on surface roughness, hardness and microleakage of resin composite restorations. Oper Dent. 2006;31:11-7.

29- Zanchi CH, Carvalho RV, Rodrigues Junior SA, Demarco FF, Burnett Júnior LH. Shrinkage stress of three composites under different polymerization methods. Braz Oral Res. 2006,20:137-42. 